\title{
Assessment of substance use and associated factors among high school and preparatory school students of Ginnir Town, Bale Zone, Southeast Ethiopia
}

\author{
Ahmed Yasin Mohammed \\ Department of Public Health, College of Medicine and Health Science, Madawalabu University, Bale Goba, Ethiopia
}

Email address:

ahmedyassinmoha@yahoo.com

To cite this article:

Ahmed Yasin Mohammed. Assessment of Substance Use and Associated Factors among High School and Preparatory School Students of Ginnir Town Bale Zone, Southeast Ethiopia. American Journal of Health Research. Vol. 2, No. 6, 2014, pp. 414-419.

doi: 10.11648/j.ajhr.20140206.25

\begin{abstract}
Substance use remains high among youth and young adolescent in high school and college. The use of alcohol, Khat and Tobacco by high school and college student can be harmful, leading to decrease academic performance, increase risk of contributing HIV and other sexual transmitted disease. However, the magnitude of substance use and other factor associated with it has not been investigated among high school and preparatory school students in the country. The objective of this study is designed to assess the prevalence and associated factor of substance use among high school and preparatory schools of Ginnir town. Cross sectional study using a self administrated questionnaire was conducted to collect information about substance use among high school and preparatory school students in Ginnir town by taking total sample size of students. The result shows that total of 220 students were included in the study out of this most of the respondents were male 125(56\%).The prevalence of substance use among male respondents were $31.2 \%$ ever drunk alcohol,48\% khat chew and $12 \%$ ever smoke cigarette .while $8.4 \%, 8 \%$ and $7 \%$ of female were ever drunk alcohol ,khat chew and smoke cigarette respectively. Problem associated with substance use include violence (39.1\%), any medical problem $(42.1 \%)$, poverty (54.3\%). It can be concluded that the prevalence of substance use among high school and preparatory students was high and causes social impact such as violence, crime and poor school performance and medical impact such as unprotected sex, mental problem. Strong measure need to be taken for greater awareness among respondents to reduce its prevalence and impacts. (Social, medical, economic).
\end{abstract}

Keywords: Alcohol, Khat Leaves and Tobacco

\section{Introduction}

Use of substance such as alcohol, khat leaves and Tobacco has become one of the rising major public health and socioeconomic problem worldwide. It is estimated that $90 \%$ of global population aged 12 or order are classified with dependency on psycho active substance (1). The history of drug use in Africa relatively short, however the abuse of drug in Africa is escalating rapidly for tobacco, alcohol and khat abuse to users to wide range of drug users (2).

Alcohol consumption is important risk factor for morbidity and mortality and social harm in the world (1-2) leading to 25 million death each year (3). Alcohol consumption is responsible for approximately $4 \%$ of global burden death. This burden is higher in high income countries and among male, accounting for $11 \%$ of all male death in WHO European region in 2004.Even though, the problem is said to be increase in developing world, there are no significant data on alcohol use and its consequence in many developing countries. (4) Khat is a natural stimulant from catadulis plant that is cultivated in the republic of Yemen and most of countries in east Africa. (5)

The use of substance such as alcohol, Khat, Tobacco has become one of the rising major health problem and socio economic problem in our country. Alcohol specially in high dose when combined with khat or tobacco continuous to claim the life of many people. Heavy consumption of khat is associated with euphoria, hyper activity, anorexia, insomnia, lethargy and depression. In addition to combined use of alcohol and khat could increase sexual risk behaviour contributing to spread of HIV. The problem of substance use has historically been linked to high school and preparatory school students due to the prevalence of substance use by the community in Ginnir town. The use of alcohol, Khat and 
tobacco among adolescent can be harmful leading to decrease academic performance, increase risk of contracting HIV and STI and other Psychotic disorder such as lethargy, hopelessness, and insomnia (5-6). Furthermore it exposes students to legal repercussion or Jeopardize their enrolment at high school and preparatory school. Substance use behaviour among high school and preparatory school students have an important implication for the health of general population, since students are important model item of health related behaviour.

Tobacco consumption has been the main risk factor for chronic disease such as lung cancer, chronic lung disease, DM and cardio vascular disease. However, it is use has become a growing corner among high school and preparatory school students in many parts of Ginir town. Adolescent smoking is also important as it is associated with short term health effect, such as incident and exacerbation of asthma, un healthy life style or social problem and un protected sex (6). Alcohol consumption is important risk factor for morbidity and mortality and social harm in the world.

The use of substance like alcohol, tobacco and khat has become one of the rising health problems among high school and preparatory school student in Ginir town. Because of this assessing the prevalence and associated factor of substance usage among high school and preparatory school student will give us baseline data. This study also shows the significance of the problems among Ginir high school and preparatory students of substance users.

\section{Methodology}

\subsection{Study Area and Study Period}

This study was conducted at high school and preparatory school of Ginnir town. Ginnir town is one of the three administrative town of Bale Zone which is located at $570 \mathrm{~km}$ from Addis Ababa to Southeast of Ethiopia with a total population of 35,000. The climate condition of Ginnir town is Weina Dega. Ginnir town has one high school and one preparatory school with a total of 2004 students. The study was conducted from March 1 to March 15, 2014.

\subsection{Study Design}

Cross- sectional study was conducted to assess the prevalence and associated factor of substance use among high school and preparatory school of students.

\subsection{Population}

Source population: All students of high school and preparatory school students in Ginnir town.

Study population: Systematically selected students from sampling frame by using lottery method.

\subsection{Sample Size Determination}

Sample size determination: Sample size was determined by using simple proportion formula with an assumption of:
$\mathrm{P}=20 \%$ (prevalence of proportion research done in Butajira) $\mathrm{CI}=95 \%$, Marginal error $=5 \%$ (6). Then the sample sizes become:-

$$
\mathrm{n}=\mathrm{Z}_{1 / 2}{ }^{2} \mathrm{P}(1-\mathrm{P}) \neg=\frac{(1.96)^{2} \times 0.2(1-0.2)}{(0.05)^{2}}=246
$$

Since the Total number of students in Ginnir high school and preparatory school was less than 10,000 , So we use the following adjustment for the sample size.

$$
\begin{aligned}
& \mathrm{S}=\mathrm{n} * \mathrm{~N} \\
& \neg \mathrm{n}+\mathrm{N}
\end{aligned}
$$

Where: $\mathrm{n}=$ sample size

$\mathrm{N}=$ Total number of high school and preparatory school students

Then the final sample size became 220 .

Sampling Method: First study subject was stratified according to their academic level. Then the sample size was proportionally allocated for each randomly selected class. Using the student roster from the register of school as sampling frame study subject was selected randomly.

Table 1. Stratification of students among high school and preparatory school students in Ginnir Town 2013.

\begin{tabular}{lll}
\hline Grade & Total number of students & Sample \\
\hline 9 & 917 & $220 \times 917=1002004$ \\
10 & 691 & $220 \times 691=762004$ \\
11 & 270 & $220 \times 270=302004$ \\
12 & 126 & $220 \times 126=142004$ \\
\hline
\end{tabular}

\subsection{Data Collection Methods / Procedure}

Data was collected using semi structured questionnaire which include question about prevalence of substance use and associated factors. Five well oriented data collectors will involve during data collection to assist on helping students understanding questions which might be vague on differently perceived. Data collectors were mainly health professional who can elaborate some of the content of questionnaire to be used. Data collection will be supervised by supervisor selected from Mada Walabu University.

\subsection{Data Quality Control}

Pre-test was conducted on selected populations which are out of study population to assess the reliability of data collection instrument. The collected data was cheeked daily during data collection in order to assess the completeness of questionnaires.

\section{Plan for Data Analysis and Processing}

Data collected was analyzed manually by using scientific calculator. Then the result was presented using frequency table and figures. 


\subsection{Ethical Consideration}

Ethical clearance was obtained from Madawalabu University college of Medicine and Health science ethical review committee to high school and preparatory school in Ginnir town, Bale Zone. All student participate in the study was asked for their willingness to participate in the study. Additionally, confidentiality of all the data to be obtained was seriously respected.

\section{Results}

Table 2. Percentage distribution of study population by Socio-demographic and economic background, 2013.

\begin{tabular}{|c|c|c|}
\hline Variable & Frequency & Percentage \\
\hline \multicolumn{3}{|l|}{ Age } \\
\hline $10-14$ & 7 & 31.8 \\
\hline $15-19$ & 19 & 88.60 \\
\hline $20-24$ & 18 & 18.36 \\
\hline \multicolumn{3}{|l|}{25 and above } \\
\hline \multicolumn{3}{|l|}{ Sex } \\
\hline Male & 125 & 56.8 \\
\hline Female & 95 & 43.2 \\
\hline \multicolumn{3}{|l|}{ Religion } \\
\hline Orthodox & 106 & 48.18 \\
\hline Muslim & 105 & 47.72 \\
\hline Protestant & 7 & 3.18 \\
\hline Other & 2 & 0.90 \\
\hline \multicolumn{3}{|l|}{ Marital status } \\
\hline Single & 205 & 93.1 \\
\hline Married & 15 & 6.9 \\
\hline \multicolumn{3}{|l|}{ Educational level } \\
\hline Grade 9 & 100 & 45.4 \\
\hline Grade 10 & 76 & 34.5 \\
\hline Grade 11 & 30 & 13.6 \\
\hline Grade 12 & 14 & 6.3 \\
\hline \multicolumn{3}{|l|}{ Fathers Educational status } \\
\hline Illiterate & 30 & 13.64 \\
\hline Primary & 47 & 21.36 \\
\hline Secondary & 42 & 19.09 \\
\hline Diploma & 50 & 22.72 \\
\hline Degree and above & 51 & 23.18 \\
\hline \multicolumn{3}{|l|}{ Mother education } \\
\hline Illiterate & 58 & 26.36 \\
\hline Primary & 56 & 24.45 \\
\hline Secondary & 56 & 24.45 \\
\hline Diploma & 36 & 16.36 \\
\hline Degree and above & 14 & 6.36 \\
\hline \multicolumn{3}{|l|}{ Father occupational status } \\
\hline Governmental employee & 70 & 31.82 \\
\hline Merchant & 43 & 19.54 \\
\hline Farmer & 93 & 42.27 \\
\hline Other (NGO) & 14 & 6.36 \\
\hline \multicolumn{3}{|l|}{ Mather occupational status } \\
\hline Governmental employee & 30 & 13.64 \\
\hline Merchant & 54 & 24.54 \\
\hline Farmer & 32 & 14.54 \\
\hline House wife & 104 & 47.27 \\
\hline \multicolumn{3}{|l|}{ Family source of income } \\
\hline Governmental Employee & 62 & 28.18 \\
\hline Business & 64 & 29.09 \\
\hline Agriculture & 83 & 37.72 \\
\hline NGO & 9 & 4.09 \\
\hline Urban & 114 & 51.82 \\
\hline Rural & 106 & 48.18 \\
\hline
\end{tabular}

Total of 220 students were included in the study out of this majority of them found within age group of 20-24 followed by age group of 15-19 which is $195(88.60 \%)$ and 18 (8.2\%).On the other hand, the sex related variable indicate that male respondents account $125(56.82 \%)$ where as females 95 $(43.28 \%)$ Regarding, ethnicity majority $160(72.7 \%)$ of them were Oromo followed by Amhara $54(24.5 \%)$ and the rest were Tigre and Somali $4(1.8 \%)$ and $2(0.9 \%)$ respectively. Concerning religion majority $16(48.18 \%)$ were orthodox followed by Muslim $105(47.72 \%)$ and the rest were protestant $7(3.18 \%)$ and $2(0.9 \%)$ respectively Educational level of respondent indicate $100(45.4 \%)$ were grade $9,76(34.5 \%)$ were grade $10,30(13.6 \%)$ and $14(6.3 \%)$ grade 11 and grade 12 respectively. Regarding, marital status majority 205 (93.1\%) were single and the rest $15(6.9 \%)$ were married. Respondents father educational status indicate that $51(23.18 \%)$ were degree and above followed by diploma $50(22.73 \%)$. In relation to this respondents mother occupational status, majority 58(26.36\%) were illiterate followed by $56(24.45 \%)$ were primary and secondary school with the same result. Concerning respondents father occupational status, most of them 93 (42.27\%) were government employee followed by 70 ( $31.82 \%)$. In relation to this mother occupational status, majority 104 (47.27\%) were house wife followed by $54(24.54 \%)$ were merchant. Total of 220 respondents, $114(51.82 \%)$ came from rural while 106 $(48.18 \%)$ came from urban. Regarding, family source of income $83(37.72 \%)$ from agriculture based followed by $64(29.09 \%)$ from Business. (Table 2)

Total of 220 respondents 165 (75\%) had information about substance use while $55(25 \%)$ had no information about substance use. Regarding information about types of substance use majority $10(31.66 \%)$ heard information about tobacco followed by 98 (30.72\%) about khat chewing and the rest $77(24.14 \%)$ and $43(13.45)$ heard about alcohol and shisha respectively. concerning introduction of substance use to respondents, by nuclear family $81(41 \%)$, by friend 62 (31.63), by relative 29 (14.7\%) and by them self 24 (12.25). Regarding reason for substance use of respondents 66 (32.35\%) to relief stress, $62(30.14 \%)$ to relax, $41(10.09)$ peer pressure, $20(9.8 \%)$ desire to experience and $15(7.35 \%)$ to cope with problem. (Table 3)

Table 3. Distribution of study subject according to information about substance use and type, introduction and Reason for use, 2013.

\begin{tabular}{llll}
\hline Variables & Response ategory & Frequency & Percentage \\
\hline Heard about & Yes & 165 & 75 \\
substance & No & 55 & 25 \\
& Alcohol & 77 & 24.14 \\
Types of substance & Tobacco & 101 & 31.66 \\
Heard & Chat & 98 & 30.72 \\
& Other (shisha) & 43 & 13.45 \\
Who introduce & Friends & 62 & 31.63 \\
you & Nuclear Family & 81 & 41.33 \\
& Relatives & 29 & 14.7 \\
& Other (by him self & 24 & 12.25 \\
& To relax & 62 & 30.4 \\
Reason for use & To relieve stress & 66 & 32.35 \\
& Desire to experience & 20 & 9.8 \\
& Pressure & 41 & 10.09 \\
& Other (cope to & 15 & 7.35 \\
\hline
\end{tabular}


Out of 220 respondents $66(30 \%)$ were had friend who drunk alcohol and $154(70 \%)$ had no friend who drunk alcohol from 66 respondents about 47 (376) male and 19 (20\%) of female had friend who drunk alcohol. About 39 (31.2) of male and $8(8.4 \%)$ of female respondents were ever drunk alcohol while the remaining $86(68 \%)$ of male and 87 $(91.6 \%)$ of female were not ever drunk alcohol. with regarding to alcohol past user about 39 (30.2\%), 30 (24\%), $16(12.8 \%)$ of male were drunk alcohol in the last 12 month, last 30 day, last 7 day respectively. while $7(7.4 \%), 3(3 \%), 5$ $(5.3 \%)$ of female were drunk alcohol in the last 12 month, last 30 days and last 7days respectively. About 20 (16\%) of male and $4(4.2 \%)$ of female were currently drunk alcohol, while $105(84 \%)$ of male and $91(95 \%)$ of female were drunk alcohol currently (Table4)

Table 4. Percentage distribution of study subject according to their alcohol use depending on their sex alcohol use depending on their sex 2013.

\begin{tabular}{|c|c|c|c|c|c|}
\hline \multirow{3}{*}{ Alcohol use } & \multirow{3}{*}{ Response } & \multicolumn{4}{|l|}{ Sex } \\
\hline & & \multicolumn{2}{|c|}{ Male } & \multicolumn{2}{|c|}{ Female } \\
\hline & & $n_{0}$ & $\%$ & $n_{0}$ & $\%$ \\
\hline \multirow{2}{*}{$\begin{array}{l}\text { Have friend who } \\
\text { drink alcohol }\end{array}$} & Yes & 47 & 37.6 & 19 & 20 \\
\hline & No & 78 & 62.4 & 76 & 80 \\
\hline \multirow{2}{*}{ Ever drunk alcohol } & Yes & 39 & 31.2 & 8 & 8.4 \\
\hline & No & 86 & 68.8 & 87 & 91.6 \\
\hline \multirow{4}{*}{$\begin{array}{l}\text { Drunk alcohol in the } \\
\text { last } 12 \text { month } \\
\text { Drunk alcohol in the } \\
\text { last } 30 \text { days }\end{array}$} & Yes & 39 & 31.2 & 7 & 7.4 \\
\hline & No & 86 & 68.8 & 88 & 92.6 \\
\hline & Yes & 30 & 24 & 3 & 3 \\
\hline & No & 95 & 76 & 92 & 97 \\
\hline \multirow{4}{*}{$\begin{array}{l}\text { Drunk alcohol in last } \\
7 \text { days } \\
\text { Currently drunk } \\
\text { alcohol }\end{array}$} & Yes & 16 & 12.8 & 5 & 5.3 \\
\hline & No & 109 & 87.2 & 90 & 94.7 \\
\hline & Yes & 20 & 16 & 4 & 4.2 \\
\hline & No & 105 & 84 & 91 & 95.8 \\
\hline
\end{tabular}

Table 5. Percentage distribution of study subject according to their Tobacco uses depending on their sex, 2013.

\begin{tabular}{|c|c|c|c|c|c|}
\hline \multirow{3}{*}{ Tobacco use } & \multirow{3}{*}{ Response } & \multicolumn{4}{|l|}{ Sex } \\
\hline & & \multicolumn{2}{|c|}{ Male } & \multicolumn{2}{|c|}{ Female } \\
\hline & & $\mathbf{n}_{\mathbf{0}}$ & $\%$ & $\mathbf{n}_{\mathbf{0}}$ & $\%$ \\
\hline \multirow{2}{*}{$\begin{array}{l}\text { Have friend who } \\
\text { smoke }\end{array}$} & Yes & 20 & 16 & 11 & 12 \\
\hline & No & 105 & 84 & 84 & 88 \\
\hline \multirow{2}{*}{ Ever smoke } & Yes & 15 & 12 & 7 & 7 \\
\hline & No & 110 & 88 & 88 & 93 \\
\hline \multirow{2}{*}{$\begin{array}{l}\text { Smoke last } 12 \\
\text { month }\end{array}$} & Yes & 10 & 8 & 8 & 8 \\
\hline & No & 115 & 92 & 87 & 92 \\
\hline \multirow{2}{*}{ Smoke last 30 days } & Yes & 15 & 12 & 0 & - \\
\hline & No & 110 & 88 & 95 & 100 \\
\hline \multirow{2}{*}{ Smoke last 7 days } & Yes & 7 & 6 & 1 & 1 \\
\hline & No & 118 & 94 & 94 & 99 \\
\hline \multirow{2}{*}{ Currently smoke } & Yes & 15 & 12 & 2 & 2 \\
\hline & No & 110 & 88 & 93 & 98 \\
\hline
\end{tabular}

Among 220 respondents 20 (16\%) of male and $11(12 \%)$ of female had friend who smoke cigarettes while $105(84 \%)$ of male and $84(84 \%)$ of female had no friend who smoke cigarettes .concerning students who ever smoke cigarette 15 (12\%) of male and $7(7 \%)$ of female, while $110(88 \%)$ of male and $88(93 \%)$ of female were not ever smoke cigarettes. About $10(8 \%)$ of male and $8(8 \%)$ of female were smoke cigarette in the last month while $115(92.5 \%)$ of male and 87 (92\%) of female were not smoke cigarette in the last 12 month .Regarding smoke cigarettes in the last 30 days about $15(12 \%)$ were male and none of female smoke cigarettes in the last 30 days .About 7(6\%) and $1(1 \%)$ of male and female were smoke cigarettes in the last 7 days respectively y. While $118(94 \%)$ of male and $94(99 \%)$ female were not smoke cigarettes in the last 7 day .Concerning current smokers, $15(12 \%)$ and $2(2 \%)$ were male and female respectively. (Table 5)

Out of 220 respondents $80(64 \%)$ of male had friend who chew khat and $12(13 \%)$ of female had friend who chew khat, while $45(36 \%)$ of male and $83(87 \%)$ of female were those who had no friend chewing khat. Regarding ever khat chewer $60(48 \%)$ of male and $8(8 \%)$ of female while $65(42)$ female and $87(92 \%)$ of female were not ever khat chewer. with regard to past khat chewers about 49(39), 45(36),30(24\%) of male were chew khat in the last 12 month. 30 days and last 7 days respectively. Regarding khat chewing currently 55 (44) of male and $12(13 \%)$ of female were khat chewing. About $70(56 \%)$ of male and $83(87 \%)$ of female were not khat chew currently. (Table6)

Table 6. Percentage distribution of study subject according to their Khat use depending on their sex.

\begin{tabular}{|c|c|c|c|c|c|}
\hline \multirow{3}{*}{ Khat use } & \multirow{3}{*}{ Response } & \multicolumn{4}{|c|}{ Sex } \\
\hline & & \multicolumn{2}{|c|}{ Male } & \multicolumn{2}{|c|}{ Female } \\
\hline & & $n_{0}$ & $\%$ & $n_{0}$ & $\%$ \\
\hline \multirow{2}{*}{$\begin{array}{l}\text { Have friend who chew } \\
\text { Khat }\end{array}$} & Yes & 80 & 64 & 12 & 13 \\
\hline & No & 45 & 36 & 83 & 87 \\
\hline \multirow{2}{*}{ Ever chewing khat } & Yes & 60 & 48 & 8 & 8 \\
\hline & No & 65 & 42 & 87 & 92 \\
\hline \multirow{4}{*}{$\begin{array}{l}\text { Chew khat with in the } \\
\text { last } 12 \text { month } \\
\text { Chew khat with in the } \\
\text { last } 30 \text { month }\end{array}$} & Yes & 49 & 39 & 2 & 2 \\
\hline & No & 76 & 61 & 93 & 98 \\
\hline & Yes & 45 & 36 & 18 & 19 \\
\hline & No & 80 & 64 & 87 & 81 \\
\hline \multirow{2}{*}{$\begin{array}{l}\text { Consumed khat with } \\
\text { in the last } 7 \text { days }\end{array}$} & Yes & 30 & 24 & 11 & 12 \\
\hline & No & 95 & 76 & 84 & 88 \\
\hline \multirow{2}{*}{$\begin{array}{l}\text { Currently chewing } \\
\text { khat }\end{array}$} & Yes & 55 & 44 & 12 & 13 \\
\hline & No & 70 & 56 & 83 & 87 \\
\hline
\end{tabular}

Table 7. Distribution of study subject according to awareness about impact of substance use, 2013.

\begin{tabular}{llll}
\hline Variables & Response & Frequency & Percentage \\
\hline \multirow{2}{*}{ Social impact } & Yes & 197 & 89.5 \\
& No & 23 & 10.5 \\
& Divorces & 44 & 22.3 \\
& Violence & 77 & 39.1 \\
Social impact & Crime & 47 & 23.8 \\
& Poor school & 29 & 14.72 \\
& performance & & \\
& Any medical problem & 83 & 42.13 \\
Medical impact & Un protected sex & 67 & 34.01 \\
& Mental problem & 41 & 20.8 \\
Economical & Others & 6 & 3.04 \\
impact & Extravagancy & 90 & 45.6 \\
\hline
\end{tabular}

Total of 220 respondents 197 had information about impact of substance use while $23(10.5 \%$ ) had no information about substance uses. Regarding social impact of substance use $77(39.1 \%), 47(23,8 \%), 44(22.3 \%) 29(14.72 \%)$ where violence, crime, Divorce and poor school performance respectively. Concerning medical impact about 83 (42.13), 67(34.01), 41(20.8) and 6(3.04) where any medical problem, UN protected sex, mental problem and others (physical emaciated) respectively. Regarding economic problem 
arising from substance use about 90(45.68\%) were extravagancy and about $107(54.32 \%)$ was poverty. (Table 7)

Introduction of substance use indicate $81(41.3 \%)$ respondents were introduced by nuclear family followed by $62(31.63 \%)$ were introduced by friend and the rest $29(14.7 \%)$ by relatives and $24(12.25 \%)$ by them self. Our report rate was much lower regarding introduction of substance by friend and relative when comparable with study report from western Kenya college student. In western Kenya among college students $75.1 \%$ were introduced by friend followed by $23.50 \%$ by relatives and very small percentage $1.4 \%$ were introduced by nuclear family (10).

Introduction of substance use according to our study in Ginnir high school and preparatory school students were highly related to nuclear family $(41.3 \%)$ but, among college students in western Kenya high percentage of substance introduction related to friend. Explanation for high percentage of substance introduction in this study was, students family in Ginnir town were highly addicted to substance use especially tobacco and Khat chewing.

Regarding reason for substance use high percentage of our respondents $66(32.75 \%)$ were to relieve from stress followed by $62(30.44 \%)$ to relax and low percent $15(7.35 \%)$ of students use substance to cope with problem. This finding was much lower when comparable with report from college student in western Kenya (10). In western Kenya high percentage $62.2 \%$ of students use substance to relax followed by $60.8 \%$ to relieve stress and low percentage $38.9 \%$ peer pressure and to cope with problem by the same result. This raises the possibility that intervention that help young people to use their time less productively would increase the incidence of substance use.

The prevalence of substance use among high school and preparatory school students in Ginnir town was about $21 \%$ drank alcohol past 12 month and the rest $15 \%, 9.54 \%$ and $10.9 \%$ were drank alcohol past 30 days, last 7 day and current drinker respectively. Our finding of ever and past 12 month alcohol drinking of $21.3 \%$ and $10.4 \%$ respectively seen to be lower than the report from Addis Ababa (6) which indicate alcohol drinking of prevalence of $45.7 \%$. and $26.5 \%$ in the same order. It is also lower than $41.8 \%$. Part 30 day drinking by high school student in the USA and $51.9 \%$ ever drinking prevalence of alcohol use report among secondary school student in Kisumu town Kenya (11). The primarily reason for the comparatively lower alcohol drinking level in this study could be lack of access due to cultural reason.

The prevalence of khat chewing among high school and preparatory students in Ethiopia is very high. Study conducted in Ethiopia revealed that $26.7 \%$ life time prevalence of khat chewing among high school and preparatory school students (22) as our study indicated that $48 \%$ of male and $8 \%$ of female were ever khat chewing, $39 \%$ of male and $2 \%$ of female were khat chewing in last 12 month about $36 \%$ of male and $19 \%$ female were khat chewing in last 30 days, $44 \%$ of male and $3 \%$ female were current khat chewer. Our finding indicated that khat use in the past 12 month and 30 days was $39 \%$ male and $2 \%$ of female, $36 \%$ of male and $19 \%$ of female respectively. About $44 \%$ of male and $13 \%$ of female were current chewer. This also indicated current khat chewer higher than past khat chewer in the last 12 months and 30 days). Study conducted in Addis Ababa private school found prevalence of khat chewing was $57.7 \%$ ( 16). Our study indicated khat chewer in Ginnir high school and preparatory school students higher than that of Addis Ababa reports. Our result indicated that high percent of male $48 \%$ were ever khat chewer than that of female $(8 \%)$ in Ginnir high school and preparatory students. The main explanation for this was probably that khat was cultivated highly in nearby Ginnir town. Reason for this was khat widely cultivated nearby Ginnir town.

Regarding to our study cigarette smoking among high school and preparatory school student in Ginnir town, about $12 \%$ of male and $7 \%$ of female were ever smoke cigarette, $8 \%$ of male and $8 \%$ of female were smoke cigarette in the last 30 days, $6 \%$ of male and $1 \%$ of female were smoke cigarette in the last 7 days, $12 \%$ of male and $2 \%$ of female were current smoker. This study indicate that equal number of male $(12 \%)$ were ever smoke cigarette with current ever smokers. Study conducted in North West Ethiopia indicates current use of cigarette smoking was reported by $21 \%$ of college students. As our result indicated study conducted in North West Ethiopia was high than our results. Another study conducted in school rural Zambia Adolescents, the prevalence of cigarette smoking was reported $27 \%$ (7). This also much high than our finding .Concerning negative effect attributed to substance use: among social impact 77 (39.1\%) violence while 47)23.8\%) crime. Among medical impact 88 $(42.13 \%)$ engaged in unprotected sex. Study report in western Kenya show that $60.5 \%$ engaged in unprotected sex and $55.2 \%$ experienced any medical problem over $60 \%$ of the student in Kenya reported engaging in scuffles, loss and damage to property (10). In this study among Ginnir high school indicate that $107(54.32 \%)$ engaging in poverty while $90(45.7 \%)$ experienced extravagancy. In 1987 medical student survey in USA also found similar effect of substance like violence, crime, any medical problem, unprotected sex, poverty and extravagancy.

The study was conducted in purposively selected one woreda which might not represent the Bale zone. As the study title is sensitive the student might not reflect the actual figure. The method design by itself has its own limitation because it doesn't show cause and effect relationship.

\section{Conclusion and Recommendation}

In general, substance use was found to be prevalent among students in this study. We have demonstrated that the prevalence of current Khat chewing was slightly high. The number of study population who ever had chew Khat, drink alcohol, smoke cigarette was very high.

Therefore the negative effect of attribute to substance use were any medical problem , economic problem like poverty and social problem like violence had higher impacts.

Based on our study result we recommend that: Measure 
should be arranged for raising awareness of the students about the complication of substance use. The Ginnir town administrator should construct youth recreational area. Youth association to stand for common good.

\section{References}

[1] Rehms, Room R, Monteiro M et al. Alcohol as a risk factor for global burden of disease. Eur Addict Res. 9(4), 2003, 157164.

[2] Rehmj, Mothers C et al. Global burden of disease and injury and economic cost attributable to alcohol use and alcohol use disorder. Lancet, 373 (9682), 2009, 2223-2233.

[3] WHO.Global status report on alcohol. Mental health and substance abuse Geneva: world Health organization: 2011.

[4] Newcomb MD, Maddahian E et al. Risk factor for drug use among adolescent: concurrent and langitudual analyses, $A M S$ Public Health.76, 1986,525-531.

[5] Volkow ND, Li TK. Drugs and alcohol: Treating anbd preventing abuse, addiction and their medical consequence. Pharmacology and Therapentic, 108, 2005,3-17.

[6] Kassaye M, Sherief TH, Ghimja F, Teklu F. Drug use among school students in Addis Ababa and Butajira. Ethiopian journal of Health development, 13,1999, 101-106.

[7] OdejideAo. Status of drug use in Africa: A review. International journal of Mental Health. 4,2006,87-102.

[8] Kenna GA, Wood MD.Risk factor for alcohol and other drug use. Substance use Treatment, prevention, and policy 2008, $3: 3$.
[9] Welhsler H, Ruipotti NA et al. Increased level of cigarette use among college students a cause for national concern. JAMA, $280,1998,1673-1678$.

[10] Odek-ogunde $M$ et al. Prevalence of substance use among students in a Kenyan university: a preliminary report.East Afr med j, 76, 1999, 301-306.

[11] Kuria MW. Drug abuse among urban ar compared to ruler secondary school students in Kenya: a short communication. East Afr Med, 1996.

[12] Rudatsikira, E, Abdo A, Muula. As: prevalence and determinants of adolescent tobacco smoking in Addis ababa, Ethiopia. BMC public Health, 7, 2007,176.

[13] Center for disease control and prevention: Global Tobacco surveillance system (GTSS): purpose, production, and potential's gch health. $75,2005,15-24$.

[14] Ogwell AE, Astrom AN.Hangejorden O:socio demographic factor of pupils who use tobacco in randomly selected primary school in Nairobi Province, Kenya East Afr meds. 80, 2003, 235-241.

[15] Madu SN, Mattla MQ. Illicit drug use, cigarette smoking and alcohol drinking behaviour among a sample of high school adolescent in the Petersburg area of the Northern province, south Africa, J Adolescent .26,2003, 121-136.

[16] Odek-ugunda M, Pandae-leak D.Prevalence and risk factor of substance use: preliminary report. East Afr Med. 78, 1999, 400-402.

[17] Milikan LE. Alcoholism among health professionals: prevalence and special problem. Clinics in dermatology.17, 1999, 361-363.

[18] Tesema T. the assessment of substance abuse and predisposing factor in Butajira. 2003, 22-31. 